\title{
Exégesis y teología en la encrucijada. Teología feminista e interpretación feminista de la Biblia: una aproximación
}

\author{
Virginia R. Azcuy \\ FACULTAD DE TEOLOGÍA \\ UNIVERSIDAD CATÓLICA ARGENTINA \\ INVESTIGADORA INVITADA DEL CENTRO TEOLÓGICO MANUEL LARRAÍN
}

"En esto llegaron sus discípulos y se sorprendian de que hablara con una mujer. Pero nadie le dijo: “Qué quieres?" "QQué hablas con ella?"》 (Jn 4,27)

\section{A MOdo De PUnTO DE PARTIDA}

«La aparición de la visión feminista de la interpretación bíblica se cuenta entre las más significativas novedades que hoy tenemos en los estudios bíblicos. Durante las tres últimas décadas ha crecido en proporción geométrica el número de intérpretes que leen las Escrituras desde perspectivas explícitamente feministas y en beneficio de mujeres y varones. Estos intérpretes lanzan un desafío a la vez que enriquecen a la Iglesia que trata de adaptar la Biblia a las necesidades de estos tiempos», así co-

\footnotetext{
Según Raymond E. Brown, esta pregunta de los discípulos ante Jesús, al verlo hablar con la samaritana, "puede muy bien ser la pregunta cuyo momento ha llegado a la iglesia de Jesucristo», Cf. "Apéndice II: Función de las mujeres en el cuarto evangelio", en: La comunidad del discipulo amado (Salamanca 1996), 177192, 192. La actualidad del tema de la/s mujer/es y su relación con el feminismo, referido a la lectura de la Biblia, queda de relieve en el Documento de la Pontificia Comisión Bíblica, La interpretación de la Biblia en la Iglesia. Discurso de su Santidad el Papa Juan Pablo II y Documento de la Pontificia Comisión Bíblica (Buenos Aires 1993), en relación con el acercamiento feminista entre las aproximaciones contextuales. Este artículo intenta una aproximación a este acercamiento, «una búsqueda orientada según un punto de vista particular» (Introd., B, Nota 1), en sintonía con el mencionado documento pontificio.
} 
mienza Carolyn Pressler (EE.UU.) su aporte sobre los estudios bíblicos feministas en el Comentario Bíblico Internacional editado bajo la dirección de William R. Farmer ${ }^{2}$. Hoy hablamos ya de casi cuatro décadas desde que se publicó el primer artículo de tema bíblico explícitamente feminista: Phyllis Trible, «Depatriarchalizing in Biblical Interpretation", Journal of the American Academy of Religion 41,1 (1973), 30-48. Con todo, la historia viene de 1895 y 1898 , cuando en el contexto del movimiento feminista de sufragistas del siglo XIX, Elisabeth Cady Stanton, hija de una familia presbiteriana a la vez que teórica y propagandista del feminismo inglés, publicó The Woman's Bible en dos tomos con su propio grupo de estudiosas ${ }^{3}$. Bajo el supuesto de que la Biblia era el fundamento de la religión misógina y de la opresión de las mujeres, Stanton preparó un conjunto de comentarios exegéticos en respuesta al discurso cristiano tradicional sobre las relaciones varón-mujer y el lugar de las mujeres en la sociedad. La gesta emancipadora de Stanton, de gran repercusión editorial en su tiempo, se reavivó en las últimas décadas del siglo $\mathrm{XX}^{4}$.

2 C. Pressler, «Sanar y transformar: estudios bíblicos feministas», en W. R. Farmer (dir.), Comentario Bíblico Internacional, Comentario católico y ecuménico para el siglo XXI (Estella, Navarra 1999), 257-263, 257.

3 Cf. J. Baubérot, «La mujer protestante», en G. Duby; M. Perrot (dir.), Historia de las Mujeres, 4. El siglo XIX (Madrid 2000), 241-258, 251; R. PAGe, "The Woman's Bible de Elisabeth Cady Stanton», en A. Loades (ed.), Teología Feminista (Bilbao 1997), 35-44.

4 Una señal de esta nueva atención que recibe Stanton puede verse en los comentarios a The Woman's Bible que anticipan el centenario de su primera edición: C. A Newsom - S. H. Ringe (eds.), The Women's Bible Commentary (Louisville 1992), una obra preparada por mujeres de tradición católica, protestante y judía, que comenta textos de cada uno de los libros de la Biblia en perspectiva feminista; y E. Schüssler Fiorenza (ed.), Searching the Scriptures, 2 vols. (New York 19931994), una investigación de ensayos de investigación bíblica escritos por mujeres de diferentes partes del mundo, que representa la atención a la diversidad que caracteriza la tercera ola del movimiento de las mujeres. Ver recensiones a esta obra por Constanza Levaggi en V. Azcuy - G. M. Di Renzo - C. Lértora Mendoza (coord.), Diccionario de Obras de Autoras. En América Latina, el Caribe y EE.UU. (mujeres haciendo teologías 1) (Buenos Aires 2007), 243ss. (en adelante Diccionario de Obras de Autoras). 
Entre 1975 y 1985, la generación pionera en EE.UU. ha producido las primeras obras que llegaron a ser influyentes a nivel global ${ }^{5}$. Entre las biblistas se destacan:

- Letty M. Russell, The Liberating Word: A Guide to Nonsexist Interpretation of the Bible, Philadelphia, Pennsylvania, The Westminster Press, 1976, una de las primeras obras de interés en el contexto del debate sobre el lenguaje inclusivo, tanto en la interpretación de la Biblia como en la liturgia ${ }^{6}$;

- Phyllis Trible, God and Rhetoric of Sexuality, Philadelphia, Fortress Press, 1978, que sin ser explícitamente feminista pone las bases para estudios posteriores que harán explícita esta óptica;

- Phyllis Bird, The Bible as the Church's Book, Philadelphia, Westminster Press, 1982, que abre una reflexión crítica sobre la relación entre la Biblia y las mujeres;

- Elisabeth Schüssler Fiorenza, In Memory of Her. A Feminist theological Reconstruction of Christian Origins, New York, Crossroad Publishing, 1983, posiblemente la obra de mayor impacto en el ámbito de la teología y la exégesis feminista;

5 En la colección editada por Teologanda, las autoras norteamericanas más estudiadas de esta generación son: Phyllis Bird (Biblia), Margaret Farley (ética), Margaret Guenther (espiritualidad), Sallie McFague (sistemática), Rosemary Radford Ruether (sistemática), Letty M. Russell (Biblia y sistemática), Elisabeth Schüssler Fiorenza (Biblia y sistemática), Sandra Schneiders (Biblia y espiritualidad). Ver un cuadro por región, generación y área de estudio en: M. Mazzini - N. RaIMonDo, «Introducción al Tomo 2», en: V. R. Azcuy - M. Mazzini - N. Raimondo (coord.), Antología de Textos de Autoras. En América Latina, el Caribe y EE.UU. (mujeres haciendo teologías 2) (Buenos Aires 2008) 7-13 (en adelante Antología de Textos de Autoras).

6 Sobre esta obra comenta Schüssler Fiorenza: «la publicación de Russell es la primera que calificaría como una interpretación bíblica feminista (...) el libro presenta un análisis feminista liberacionista de cambio y transformación (...) El libro The Liberating Word representa el primer paso que marca una orientación hacia un leccionario de lenguaje inclusivo y hacia una Nueva Versión Revisada», E. SchüssLER FiorenZA, «Reafirmación del conocimiento bíblico feminista/womanista», en C. Schickendantz (ed.), Memoria, identidades inestables y erotismo. Textos sobre género y feminismos (Córdoba 2008), 201-217, 208.

7 Mercedes Navarro Puerto sostiene que esta obra representa «un momento de inflexión en la exégesis feminista del NT», ya que "formuló preguntas que la mayoría de las exégetas feministas ya no podemos ignorar porque establecen estrechas 
- Phyllis Trible, Texts of Terror. Literary-Feminist Readings of Biblical Narratives, Philadelphia, Fortress Press, 1984, obra en la cual su autora ya se posiciona como feminista;

- Letty M. Russell (ed.), Feminist Interpretation of the Bible, Philadelphia, The Westminster Press, 1985, que reúne aportes de Brown Zikmund, Cannon, Farley, Doob Sakenfeld, Ringe, Exum, Setel, Brooks Thistlethwaite, Radford Ruether, Schüssler Fiorenza, Russell y Trible;

- Sandra Schneiders, Women and the Word. The Gender of God in New Testament and the Spirituality of Women, New York/Mahwah, Paulist Press, 1986, que ilustra -como antes Trible- la importancia de pensar a Dios desde la perspectiva de género y de plantear, desde esta base, la espiritualidad de las mujeres?

Dios, Biblia, mujeres, género, deconstrucción del patriarcado y reconstrucción feminista, lectura bíblica y espiritualidad son las claves fundamentales que se empiezan a articular en busca de una nueva hermenéutica ${ }^{10}$ que da cuenta de un nuevo sujeto en el quehacer teológico:

relaciones entre los métodos exegéticos y la hermenéutica bíblica», cf. «La exégesis feminista del Nuevo Testamento: con acento extranjero», Sal Terrae 88 (2000) 643654,645 .

8 Esta lista es interesante porque no todas las autoras son exégetas, sino teólogas (Brown Zikmund, Brooks Thistlethwaite, Radford Ruether, Russell) o moralistas (Cannon, Farley), lo cual muestra el interés general de las pioneras feministas por los estudios bíblicos y la común afiliación feminista.

9 Las obras mencionadas de Bird, Schneiders, Schüssler Fiorenza y Trible han sido recensionadas en Diccionario de Obras de Autoras, 46-53, 237-240, 240-256, $287-$ 291; los textos más significativos de las tres primeras han sido compilados y comentados en Antología de Textos de Autoras, 107-114, 439-447, 449-471. Ver Constanza Levaggi sobre Russell, Feminist Interpretation of the Bible en Proyecto 39 (2001), 436s.

10 En este cruce de temas y perspectivas, no se puede omitir la mención de algunas obras de años posteriores que tuvieron mayor impacto: R. RADFord Ruether, Sexism and God-Talk. Toward a Feminist Theology, With a new Introduction (Boston 1993); E. A. Johnson, She who is. The Mystery of God in Feminist Theological Discourse (New York 1999); I. Gebara, Rompendo o silêncio. Uma fenomenología feminista do mal (Petrópolis 2000); M. P. Aquino - D. Machado - J. Rodríguez (eds.), A Reader in Latina Feminist Theology. Religion and Justice (Austin 2002). Estas autoras han recibido estudios monográficos en el marco de la investigación de Teologanda 2003-2005, cf. V. R. Azcuy - M. García Bachmann - C. LÉrtora Mendoza (coord.), Estudios de Autoras. En América Latina, el Caribe y EE.UU. 
el feminista, en su mayoría mujeres, y también, de modo creciente, estudiosos varones. En nuestra región, merecen destacarse publicaciones teológicas de mujeres con la participación de varones como una señal del diálogo sobre nuevas perspectivas en tiempos de encrucijada ${ }^{11}$.

En la década que va de 1985 hasta 1995, mientras evolucionó la exégesis feminista norteamericana ${ }^{12}$, empiezan a estallar paulatinamente las teologías hechas por mujeres en América Latina y el Caribe, tanto en teología sistemática ${ }^{13}$ como en Biblia. Entre las pioneras en el área bíblica se encuentran: Beatriz Melano (†2004), la primera mujer con doctorado en Teología en América Latina y de tradición evangélica ${ }^{14}$, Elsa Tamez (México/Costa Rica), Carmiña Navia Velasco (Colombia), Lúcia Weiler e Ivoni Richter Reimer (Brasil). A ellas siguen las nuevas generaciones, quienes obtienen su doctorado en Teología a partir de 1999: Mercedes García Bachmann (Argentina) y Tânia Mara Vieira Sampaio (Brasil) primero, Bernardeth Caero (Bolivia) y Ahida Pilarski

(mujeres haciendo teologías 3) (Buenos Aires 2009), 45-69, 181-194, 233-245, 247-266 y 349-374 (en adelante Estudios de Autoras).

11 Cf. V. R. Azcuy (coord.), «El lugar teológico de las mujeres. Un punto de partida», Proyecto 39 (2001), 445pp. «En la encrucijada del género. Conversaciones entre Teología y disciplinas», Proyecto 45 (2004) 317pp. V. R. Azcuy - M. A. López L. Riba de Allione, "Con las alas del alma...”. Ecos del I Congreso de Teólogas Latinoamericanas y Alemanas», Anatéllei XI, 22 (2009), 191pp. D. García G. O. Vélez C. - M. del Socorro V., Reflexiones en torno al feminismo y el género (Bogotá 2004); A. Novoa - A. M. Sierra - C. Vélez C. (eds.), Sentires teológicos en perspectiva liberadora. I Congreso de Teólogas latinoamericanas y alemanas (Bogotá 2008).

12 Entre las obras de este tiempo, cf. P. BIRD, Feminism and the Bible. A critical and Constructive Encounter, Winnipeg (Manitoba 1994); S. SchneIders, Beyond patching. Faith and Feminism in the Catholic Church (New York/Mahwah 1991); E. Schüssler Fiorenza, But She Said. Feminist Practices of Biblical Interpretation (Boston 1992); P. Trible, Rhetorical Criticism. Context, Method, and the Book of Jonah (Minneapolis 1994), entre otras. Cf. Diccionario de Autoras, 49-53, 238-239, 248-251, 289-291.

13 Entre las principales teólogas latinoamericanas -de origen o residentes- están Bárbara Andrade, María Pilar Aquino, María Clara Bingemer, Isabel Corpas de Posada, Ivone Gebara, Ada María Isasi-Díaz, Anneliese Meis, María Teresa Porcile († 2001), Mary Judith Ress, Ute Seibert-Cuadra y Ana María Tepedino.

14 Ver su homenaje en M. García Bachmann, «Cuando la teología se soltó el pelo. Beatriz Melano: la primera teóloga en el Río de la Plata († 2004)», en Estudios de Autoras, 493-503. 
(Perú/EE.UU.) después, entre otras ${ }^{15}$. La más conocida entre las biblistas latinoamericanas es, sin duda, Elsa Tamez, quien muestra una clara filiación de la teología de la liberación y una peculiar preocupación por los pobres y su conexión con las mujeres como sujetos que esperan salir de la opresión, con una clara contribución en la hermenéutica bíblica ${ }^{16}$. En el Cono Sur, la biblista más destacada en la actualidad es Mercedes García Bachmann, una de las primeras de nuestro país en obtener un doctorado en Sagradas Escrituras, pastora luterana y adscripta a la teología feminista de la liberación ${ }^{17}$; su labor se concentra en la historia deuteronomista con el fin de revisar el estatus de las mujeres veterotestamentarias en relación y en diálogo con la problemática de la mujer contemporánea ${ }^{18}$. Una mirada al conjunto de los aportes bíblicos de

15 Para un balance de estas producciones estudiadas en el Programa Teologanda, ver C. Lértora Mendoza, «Biblia, género y teólogas latinoamericanas», en V. R. Azcuy - N. Bedford - M. Palacio (coord.), Huellas y cruces del camino. Diálogos sobre Método, Temas y Actoras (mujeres haciendo teologías 4) (Buenos Aires), (en prensa); en adelante se cita como Huellas y cruces del camino. También cabe mencionar a RIBLA, Revista de Interpretación Bíblica Latinoamericana, que nuclea biblistas de nuevas generaciones, cf. Diccionario de Autoras, 373-376, 403-404.407, 460-462, 476-482, 520ss., 541-544; sobre Tânia Vieira Sampaio, ver el artículo de Z. C. Insfrán, "La redención cotidiana en el mo(vi)mento de los cuerpos. Aproximación a la teología de Tânia Mara Vieira Sampaio», en Estudios de Autoras, 475-490.

16 Cf. L. Riba, «Desde la vida y para la vida. Teología feminista de la liberación según Elsa Tamez», en Estudios de Obras de Autoras, 429-450.

17 Cf. M. García Bachmann, «Mujer de valor... (Prov 31, 10-31). Elementos para una antropología bíblica desde el género", Proyecto 45 (2004), 119-132, 119. Su tesis de doctorado fue publicada bajo el título "Little women": social location of female labor in the deuteronomimistic history (Michigan 1999); ver su recensión en Diccionario de Autoras, 103-104.

18 Sobre su producción hasta el 2005, cf. Diccionario de Autoras, 103-105. 403-409; ver también: «A la búsqueda de trabajadoras en la Biblia hebraica. Algunos problemas metodológicos» RIHAO (Revista del Instituto de Historia Antigua Oriental «Dr. Abraham Rosenvasser», UBA) 12/13 (2005-2006), 171-188; «La ley y el orden. Una apreciación del material legal y cultual en el libro del Éxodo», en I. Gómez Aсевo (ed.), Relectura del Éxodo (Bilbao 2006), 215-263; «Miriam. Figura política de primer plano en el Éxodo», en M. Navarro P. - I. Fischer (eds.), La Biblia Hebrea (La Biblia y las mujeres 1) (Estela 2010), 337-378. Esta última referencia da la ocasión para mencionar otra nueva colección coordinada por Mercedes Navarro Puerto, Irmtraud Fischer, Adriana Valerio y Jorunn Økland, que ya publicó sus dos primeros tomos: además del ya señalado, M. Navarro - M. Perroni (eds.), Los Evangelios. Narraciones e historia (Estella, Navarra 2011). 
mujeres latinoamericanas permite afirmar que esta producción evidencia una fuerte influencia norteamericana y posee una fuerte orientación liberacionista y pastoral.

En la década 2001 al 2011 en el contexto argentino, ya he mencionado la colección "mujeres haciendo teologías" como producción colectiva de un grupo de teólogas del Programa de Estudios Teologanda; a ella se añade la colección "Género y Feminismos» editada por Carlos Schickendantz en la Universidad Católica de Córdoba, que ejemplifica la perspectiva inclusiva de la teología hecha por varones ${ }^{19}$. En el ámbito evangélico, se vienen desarrollando la actividad y las producciones del Foro de Teología y Género del Instituto Universitario ISEDET bajo la animación de Nancy Bedford y Mercedes García Bachmann ${ }^{20}$. En Chile, a partir de 2005, surgen otras actividades impulsadas por teólogas de la Facultad de Teología de la Universidad Católica. Actualmente, las recientes promociones de teólogas al grado académico del doctorado en Teología en el ámbito católico: Eva Reyes, Agustina Serrano y Kreti Sanhueza, así como los intercambios con otras teólogas argentinas y latinoamericanas ${ }^{21}$, parecen indicar el comienzo de una nueva etapa del florecimiento de las mujeres en el espacio académico ${ }^{22}$. Entre los teólogos chilenos que han asumido la perspectiva feminista y la reflexión

19 Sobre esta segunda colección, en seis volúmenes editados entre 2003 y 2009, cf. C. Schickendantz, «Introducción», en C. Schickendantz (ed.), Feminismo, género e instituciones. Cuerpos que importan, discursos que (de)construyen (Córdoba 2007), $13-23$.

20 La primera publicación de este colectivo es N. Bedford - M. García B. - M. Strizzi (eds.), Puntos de Encuentro, Foro sobre Teología y Género - Instituto Universitario ISEDET (Buenos Aires 2005).

21 El V Seminario Intensivo de Teologanda en Buenos Aires, con presencia de teólogas chilenas, marcó un hito importante en el «cruce de fronteras», cf. A. SERrano, «Síntesis del V Seminario Intensivo de Teologanda. Cómo hacer teología en la encrucijada» (Buenos Aires 2005), en Teología y Vida XLVII (2006), 387-391.

22 En espacios ecuménicos de animación y formación teológica, caben mencionar el colectivo Conspirando y las Semanas de Teología de las mujeres en el Centro Ecuménico Diego de Medellín. Cf. V. R. Azcuy - C. BAcher M., «Andares teológicos de mujeres latinoamericanas y latinas. Dos lecturas en instituciones y publicaciones del Cono Sur, Bogotá/Colombia y Nepantla», en M. Ескногт (ed.), Prophetie und Aggiornamento: Volk Gottes auf dem Weg. Eine internationale Festgabe für die Bischöfliche Aktion ADVENIAT (Münster 2011), 99-116. 
teológica sobre masculinidad/es, sobresale claramente la trayectoria de Diego Irarrázabal ${ }^{23}$.

En atención a la temática propuesta para el Seminario interno de profesores 2011 en la Facultad de Teología de la Universidad Católica de Chile, «Exégesis y teología al servicio de la fe hoy», quiero hacerme eco de los estudios bíblicos feministas y la pluralidad de las teologías feministas al señalar un nuevo eje que viene a incomodar y enriquecer las mutuas relaciones entre las disciplinas teológicas, a saber, el feminismo. En esta introducción, parece importante visualizar que el feminismo entraña una opción hermenéutica capaz de desafiar y transformar la exégesis y la teología, a la vez que de reunirlas bajo un mismo denominador común: la búsqueda de justicia para las mujeres, para toda criatura humana y para la creación. La cuestión de la mujer se ha manifestado claramente como "un signo de estos tiempos", desafiando el compromiso secular y creyente a favor de una vida humanamente digna para las mujeres y para todos ${ }^{24}$. Siguiendo esta perspectiva y sin pretensión de exhaustividad, en este estudio me limitaré a una presentación general de la teología feminista y a un diálogo con cuatro pioneras norteamericanas del área bíblica: Letty M. Russell, Elisabeth Schüssler Fiorenza, Phyllis Bird y Sandra Schneiders, quienes señalan caminos de hermenéutica bíblica feminista y sirven para ejemplificar las diversas formas del acercamiento feminista a la Biblia ${ }^{25}$. Agradezco especialmente los aportes de Mercedes García Bachmann, Carolina Insfrán, Celina Lértora Mendoza, Ahida Pilarski y Lucía Riba, en la investigación colectiva del área bíblica realizada en el

23 Cf. D. Irarrázabal, Renacer masculino -género en la acción teológica- (Chucuito 2000).

24 Cf. V. R. Azcuy, «Lo Spirito e i Segni di questi tempi», en Concilium 47 (2011), 123-135, 133ss.; M. Ескноцт, “"Ohne die Frauen ist keine Kirche zu machen!”. Ein Zeichen der Zeit endlich wahrzunehmen», en P. Hünermann (ed.), Das Zweite Vatikanische Konzil und die Zeichen der Zeit heute (Freiburg/Basel/Wien 2006), 103-115 (una adaptación en castellano en Huellas y cruces del camino, en prensa).

25 En otros estudios me he referido al aporte de teólogas sistemáticas: V. R. Azcuy, «Hablar rectamente de María. La hermenéutica feminista de Elizabeth A. Johnson» $\mathrm{y}$ «El futuro del compañerismo. El itinerario biográfico-teológico de Letty M. Russell», en Estudios de Autoras, 247-266; 375-394. En tanto que, actualmente, estoy profundizando en la contribución de Sandra Schneiders en relación con los estudios en espiritualidad, cf. V. R. AzcuY, "La espiritualidad como disciplina teológica. Panorama histórico, consensos y perspectivas actuales», en Teología 105 (2011), 251-280, 267ss 
Programa de Estudios Teologanda entre 2003 y 2005, que me permite una recuperación del feminismo bíblico sin ser especialista en este ámbito. También quisiera mencionar a Doris Muñoz, quien ha comentado y enriquecido mi presentación durante el Seminario interno.

\section{2. ¿Puede Venir algo bueno del feminismo? - Responde la teología FEMINISTA}

No es posible en esta presentación una recuperación histórica del feminismo, pero sí una referencia a él a partir de su recepción en la exégesis y la teología feminista ${ }^{26}$. Hablando de la Biblia como «nacida y crecida en tierra patriarcal» $y$ "preñada de imágenes y lenguaje masculino», Phyllis Trible aludía hace tres décadas a los desafíos provenientes del feminismo secular y lo describía con estas palabras: "postura crítica de la cultura a la luz de la misoginia, el feminismo es un movimiento profético que analiza el statu quo, emite un juicio e invita al arrepentimiento» ${ }^{27}$. A esto agrega que «semejante reto hermenéutico quiere entablar un diálogo recíproco con la Biblia desde su lejanía, complejidad, diferencia y contemporaneidad que sea capaz de procurar una comprensión renovada tanto del texto como del intérprete» ${ }^{28}$. El feminismo pone en marcha una empresa hermenéutica, tanto teórica como práctica, que ejerce su crítica hacia la visión patriarcal que asigna a las mujeres una posición de inferioridad y subordinación en las sociedades y en las religiones.

La definición del feminismo supone una crítica al patriarcado como camino de reconstrucción de las relaciones humanas y sociales, según María Pilar Aquino (México/San Diego, EE.UU.), una de las autoras que más ha escrito sobre teología feminista ${ }^{29}$ :

26 Retomaré, en este punto, otros artículos ya publicados: V. R. Azcuy, «El lugar de la teología feminista. Algunas perspectivas para un diálogo en el contexto argentino", en Schickendantz, Feminismo, género e instituciones, 211-236; "Una vida humanamente digna para las mujeres. Aportes teológicos para la construcción ciudadana», en M. Eckholt - S. Lerner (eds.), Ciudadanía, democracia y derechos humanos (Quito 2009), 293-331.

27 P. Trible, «Hermenéutica Feminista y Estudios Bíblicos», en A. Loades (ed.), Teología Feminista (Bilbao 1997), 45-51, 45. Este artículo, reproducido en la obra citada, fue publicado originalmente en The Christian Century 3-10 (1982), 116-118.

28 P. Trible, «Hermenéutica Feminista y Estudios Bíblicos», 45.

29 Su posicionamiento teológico ha evolucionado hacia la teología (feminista) latina, pero la considero latinoamericana en esta presentación dada su trayectoria en nues- 
«El concepto "feminista" conlleva en la actualidad variedad de significados. Aunque podría pensarse que excluye a los hombres a causa de la raíz femina (del sexo femenino, hembra) referida de inmediato a las mujeres, de hecho, el término "feminista" incluye a hombres y mujeres. La acepción más común, si bien no es de uso universal, señala que "feminista" es una persona -hombre o mujer- que cree, tanto en la exigencia de reestablecer a las mujeres como sujetos de pleno derecho en todos los ámbitos de la existencia, como en la intrínseca equivalencia de mujeres y hombres en cuanto personas constitutivas de la humanidad, dada en diferencia modal; junto con ello, busca crear las condiciones reales, actitudes sociales y estructuras socio-políticas que revelen, sostengan y preserven ambos aspectos» ${ }^{30}$.

A estas alturas de mi presentación, quiero reconocer que el uso de los conceptos feminismo, patriarcado y otros relacionados ${ }^{31}$, tiene un impacto inevitable sobre modelos de pensamiento y posiciones personales, lo cual hace que su introducción en general suscite reacciones, disputas y comentarios impredecibles. Para Marie-Theres Wacker (Münster, Alemania), "la expresión "teología feminista" contiene un programa, que en una primera aproximación es posible describir partiendo de los mismos conceptos que aparecen unidos (...) la teología feminista significa una confrontación entre la ciencia de la fe y el movimiento de liberación de las mujeres» ${ }^{32}$. La palabra "confrontación», más propia de las generaciones pioneras, se acepta cuando se reconoce que existe un sesgo patriarcal o de género en la cultura humana, sus tradiciones seculares, científicas y religiosas; si no se adquiere una conciencia de género, es decir, de la in-

tro contexto. Su visión se caracteriza en relación con el movimiento global de las mujeres por su liberación y en articulación con lo político.

30 M. P. Aquino, "Voz “Feminismo”", en C. Floristán - J. J. Tamayo (eds.), Conceptos fundamentales del cristianismo (Madrid 1993), 509-524, 511.

31 Sobre ellos y su recepción en la teología en un marco interdisciplinar se puede ver V. R. Azcuy - M. Palacio, "Glosario», en Antologías de Textos de Autoras, 594-603.

32 M. T. Wacker, "Voz “Teología feminista”", en P. Eicher (dir.), Diccionario de conceptos teológicos II (Barcelona 1990) 506-512, 506. La trayectoria de esta autora alemana se manifiesta en un compendio de interpretación feminista de la Biblia, único en su género, que reúne a sesenta exégetas mujeres de distintas denominaciones religiosas: L. Schottroff - M. T. Wacker (eds.), Kompendium Feministische Bibelauslegung (Gütersloh ${ }^{2} 1999$ ). En una revista de nuestro ámbito, se puede ver un aporte cualificado: M. T. WACKER, "Teologías, biografías e identidades nomádicas. Estudio de casos en la Biblia hebrea», en Stromata LXIV (2008) 111-121. 
equidad histórica que viven las mujeres ${ }^{33}$, difícilmente se podrá entender el feminismo. Su rechazo, muchas veces solapado mediante estrategias de descalificación o desprestigio, pone en evidencia una situación subjetiva de "ceguera de género» (gender-blind). La perspectiva de género, generalizada en las ciencias y utilizada también en teología y en exégesis, constituye precisamente un instrumental analítico que permite desocultar el sesgo de género y reconstruir las representaciones y las relaciones que se encuentran marcadas culturalmente ${ }^{34}$.

Esta dimensión crítica de la teología feminista, expresada en la palabra "confrontación", explica, en parte, las dificultades de recepción que han tenido y siguen teniendo con frecuencia estas teologías, tanto en el ámbito eclesial como en el académico universitario, aun cuando exista en ellas un ánimo evangélico. De todos modos, conviene decir que es posible plantear la teología feminista desde una clave de conversación ${ }^{35}$, como búsqueda de reconciliar la teología cristiana con la comprensión contemporánea de las mujeres a través de dos caminos: un intento de desafiar a los participantes de centros y seminarios a cambiar sus puntos de vista con respecto a la fe, la religión y la teología; y la propuesta de incentivar a las mujeres para revisar las imágenes y los símbolos de las tradiciones cristianas. Será, probablemente, una conversación crítica por más amigable que quiera ser, si es que de verdad se entiende en un sentido feminista; en caso contrario corre el riesgo de convertirse en una mera conversación que termine aceptando como dado lo construido, incluyendo las desigualdades de género que inferiorizan a las mujeres. En este punto, creo que no se debe olvidar que la razón principal que mueve

33 Cf. Programa de las Naciones Unidas para el Desarrollo (PNUD), Desarrollo humano en Chile. Género: los desafios de la igualdad (Santiago de Chile 2010); V. R. AzcuY, «Teología e inequidad de género: Diálogo, interpretación y ética en el cruce de disciplinas», en Bedford - García Bachmann - Strizzi, Puntos de encuentro, 37-63.

34 Con todo, no desconozco que bajo la categoría de género hay un amplio abanico de perspectivas que necesitan discernimiento. Para una introducción, ver V. R. AzcuY, "Teología ante el reto del género. La cuestión y el debate antropológico», en Proyecto 45 (2004) 9-37; M. García BaChMANN, «El impacto del análisis de género en la exégesis bíblica. Algunas reflexiones», en Proyecto 39 (2001), 43-57.

35 Así lo hace, por ejemplo, R. A. Coll, Christianity \& Feminism in conversation, CT, Mystic, 2001, 5-28; éste es, además, un talante propio del «feminismo cristiano constructivo", al decir de D. L. Carmody, Christian feminist Theology. A Constructive Interpretation (Oxford/Cambridge 1995). 
al movimiento feminista es superar la opresión, la discriminación y la violencia dirigida a las mujeres, enraizadas en una visión androcéntrica o masculina dominante, y contribuir positivamente a que ellas logren una vida plenamente digna ${ }^{36}$. Si existe una crítica feminista, esta encuentra su razón de ser en el sesgo de género que sostiene una desventaja real para las mujeres en diversas dimensiones de la vida. Lo importante, en definitiva, está en plantear un feminismo teológico que brote de las exigencias del Evangelio y que reclame de él la fuerza histórica de la salvación para las mujeres y para cada ser humano; este es el punto que anima mi lectura e investigación. Por eso espero que estos aportes sean semilla de reflexión, para seguir buscando juntos nuevos caminos de reconciliación y liberación para todas y todos.

\section{LA INTERPRETACiÓN FEMINISTA DE LA BibLIA}

Como introducción a esta sección, que propone un camino genético a partir de tres autoras pioneras -Letty Russell, Elisabeth Schüssler Fiorenza y Phyllis Bird-, me interesa contextualizar brevemente algunos aspectos del Documento de la Pontificia Comisión Bíblica sobre La interpretación de la Biblia en la Iglesia, de $1993^{37}$. El documento fue elaborado en un momento en que el método histórico-crítico practicado en la exégesis bíblica era objeto de discusión tanto en el mundo científico como religioso, sobre todo por ocuparse del sentido del texto bíblico en el pasado y no para el/la lector/a actual. En este contexto, la posición del documento es la de valorar el método histórico crítico, afirmar que el estudio diacrónico sigue siendo indispensable y señalar sus límites, para mostrar la necesidad de aplicar otros métodos y acercamientos ${ }^{38}$. En la conclusión del documento se resume lo principal: «la naturaleza misma de los textos bíblicos exige que, para interpretarlos, se continúe empleando el método histórico-crítico, al menos en sus operaciones principales. (...) Pero, una vez cumplida esta condición, los acercamientos sincrónicos (retórico, narrativo, semiótico y otros) son susceptibles de

36 Cf. A. Clifford, Introducing Feminist Theology (New York 2001) 13ss.

37 Al hacerlo, sigo a L. Rivas, "La Biblia y la Literatura: génesis y desarrollo de un encuentro", en Teología 81 (2003) 7-35, quien luego de un estado de la cuestión, ofrece un análisis narrativo de un texto evangélico. 
renovar la exégesis y de aportar una contribución muy útil» ${ }^{39}$. Conforme a lo requiere la perspectiva sincrónica, la segunda parte del documento dedica una amplia sección a las hermenéuticas filosóficas modernas, pero no se detiene en los métodos exegéticos y en los acercamientos ${ }^{40}$.

¿Qué se puede decir sobre el acercamiento feminista según este documento de la Pontificia Comisión Bíblica? Posiblemente, acierta Mercedes Navarro Puerto cuando responde que constituye un logro de la exégesis feminista el haber sido "legitimada oficialmente» ${ }^{41}$, aunque esto no significa que se haya alcanzado un reconocimiento científico e institucional de sus aportes. Otro aspecto del documento merece un breve comentario y es la tipología de hermenéuticas bíblicas feministas que se presenta: la forma radical, que «rechaza completamente la autoridad de la Biblia, diciendo que ha sido producida por varones para asegurar la dominación del varón sobre la mujer (androcentrismo)»; la forma neoortodoxa, que «acepta la Biblia y (es) capaz de servir, en la medida en que ella toma partido por los débiles, y por tanto también por la mujer; esta orientación es adoptada como "canon dentro del canon", para poner en claro todo lo que hay en la Biblia a favor de la liberación de la mujer, y sus derechos»; y la forma crítica, que «utiliza una metodología sutil y procura redescubrir la posición y el papel de la mujer cristiana en el movimiento de Jesús y en las iglesias paulinas; en esta época se habría adoptado el igualitarismo; pero esta situación habría sido disimulada en su mayor parte, en los escritos del Nuevo Testamento y más aún después, porque el patriarcalismo y el androcentrismo han prevalecido progresivamente» ${ }^{42}$. Aunque es difícil analizar estas caracterizaciones tan escuetas y sobre todo aplicarlas a las variadas formas de la hermenéutica bíblica feminista, se podría decir que la descripción de la forma radical parece corresponder a lo que, en general, se entiende por "teología feminista revolucionaria", radical o postcristiana, es decir, representa una ruptura con la tradición cristiana -tal es el caso, por ejemplo, de Mary

39 Pontificia Comisión Bíblica, La Interpretación de la Biblia en la Iglesia, Conclusión.

40 Cf. L. Rivas, «La Biblia y la Literatura: génesis y desarrollo de un encuentro», 13.

41 M. Navarro Puerto, "La exégesis feminista del Nuevo Testamento: con acento extranjero", 646.

42 Pontificia Comisión Bíblica, La Interpretación de la Biblia en la Iglesia, I, A, 4. 
Daly- ${ }^{43}$; la forma neoortodoxa podría vincularse con el «teología feminista cristiana reformista», ya que ella no rechaza la tradición cristiana, aunque busca reformarla -en este grupo, posiblemente podría incluirse a Letty Russell ${ }^{44}$, aunque habría que profundizar el alcance y la aplicación a este caso de la fórmula "canon dentro del canon»-; la forma crítica se podría identificar con la «teología feminista cristiana reconstruccionista", que comparte el compromiso con el cristianismo del feminismo reformista, pero lo considera insuficiente e imagina transformaciones y reconstrucciones más profundas - esta forma parece describir la posición de Elisabeth Schüssler Fiorenza y quienes siguen la misma perspectiva $-{ }^{45}$. La tercera autora que me propongo considerar, Phyllis Bird, no se deja encuadrar claramente en las tres formas descriptas, pero viene a ejemplificar de manera directa dos de las orientaciones del documento: primero, que es posible una articulación entre el método históricocrítico y la hermenéutica bíblica feminista; y segundo, que la inclusión del primero de los métodos permite evitar que la exégesis -en este caso feminista- quede dominada por sus presupuestos. De modo general, finalmente, el documento resume qué es lo que da unidad a la hermenéutica bíblica feminista en sus diferentes formas: la mujer como tema común y la búsqueda de su liberación y de su igualdad de derechos con el varón, lo cual se corresponde con un feminismo teológico liberacionista o teología feminista de la liberación.

Para iniciar el recorrido sobre las autoras elegidas, sugiero a Letty M. Russell, pastora presbiteriana. Luego de su obra pionera ya mencionada, The Liberating Word (Philadelphia 1976), que habló de superar interpretaciones sexistas que impiden a la Biblia ofrecer palabras de liberación, Rus-

43 Ver Diccionario de Autoras, 89-92, 388-389. Un importante estudio de esta autora es el realizado por A. NutT, Gott, Geschlecht und Leiden. Die feministische Theologie Elizabeth A. Johnsons im Vergleich mit den Theologien David Tracys und Mary Dalys (Münster 2010), 73-113.

44 Ver su caracterización como «teóloga feminista eclesial de la liberación» en referencia a su postura frente a la tradición, en V. R. Azcuy, "Reunirse alrededor de la mesa y del mundo”. La vida de Letty M. Russell (1929-2007)», en Estudios de Autoras, 505-509, 506ss.

45 En la triple caracterización de la teología feminista, sigo a A. M. Clifford, Introducing Feminist Theology, Maryknoll (New York 2001), 32-34. Según esta tipificación, considero que mi posición teológica podría entenderse como una aproximación a la teología feminista cristiana de tipo reformista, es decir, en diálogo con la tradición y desde la pertenencia a la institución. 
sell publicó Feminist Interpretation of the Bible (Philadelphia 1985) ${ }^{46}$ en la cual distinguió tres momentos en el camino de la interpretación feminista de la Biblia: la Palabra liberadora (The Liberating Word) en relación con las iniciativas relativas al lenguaje inclusivo y a la interpretación de la Biblia ${ }^{47}$; la liberación de la Palabra (Liberating the Word) que implica considerar a fondo las cuestiones relativas a la hermenéutica de la liberación y a la interpretación feminista de la Biblia, para evitar que la Palabra resulte opresiva para las mujeres a causa de una interpretación inadecuada, con lo cual se da paso a la búsqueda de criterios en orden a una interpretación feminista -como lo muestra en esta obra el aporte de Rosemary Radford Ruether- ${ }^{48}$; y, por último, la Palabra liberada (The Liberated Word), que invita a responder qué significa para la Biblia ser una palabra liberada: la primera respuesta de Russell, frente a la interminable tarea de una liberación de las lecturas del patriarcado, es que se debe distinguir entre la Palabra de Dios y los textos bíblicos $\mathrm{y}^{49}$, además, que la liberación es un proceso que se da en el ya sí y todavía no de la acción de Dios. En este proceso, la autora destaca cuatro acentos: (1) el trabajo crítico con los textos en el horizonte de la promesa y de la situación contemporánea, (2) una atención a los contextos e interpretación como reconstrucción de significado, (3) la comunidad de lucha que busca superar la dominación y deshumanización de la mitad del género humano, y (4) la interpretación como compromiso con las personas que sufren marginación y para las cuales es el mensaje de esperanza de la nueva creación. En definitiva,

46 Cf. L. M. Russell (ed.), Feminist Interpretation of the Bible (Philadelphia 1985), 11-18.

47 En 1979, el Consejo Nacional de Iglesias Cristianas (NCC) en EE.UU. recomienda la creación de un comité en vistas a un Leccionario de Lenguaje Inclusivo integrado por seis varones y seis mujeres, cuyo primer volumen aparece en 1983. Sobre otras iniciativas, ver V. Azcuy, «El futuro del compañerismo», 378s.

48 Cf. R. RAdFord Ruether, «Feminist Interpretation: A Method of Correlation», en L. Russell, Feminist Interpretation of the Bible, 137-146.

49 Letty Russell sostiene -como Schüssler Fiorenza- que la revelación divinamente inspirada no es idéntica con la colección de libros que se encuentra en el canon cristiano; ella considera importante plantear cómo se entiende la autoridad de la Biblia: en la visión patriarcal, ésta es vista como dominación y la Biblia puede ser utilizada para ejercer poder sobre los individuos en la comunidad; en la visión feminista, la autoridad auténtica es compañerismo y posibilita la construcción de una comunidad inclusiva. Cf. A. Clifford, Introducing Feminist Theology, 63; V. Azcuy, «El futuro del compañerismo», 386-388. 
el intento de Russell pone de manifiesto que la Palabra de Dios contiene un mensaje de liberación para las mujeres y para todos, pero que algunos textos y lecturas de la Biblia necesitan ser liberados/as de una visión sexista que oprime a las mujeres. Su planteo ilustra muy bien la conciencia feminista de las primeras autoras, que busca poner al descubierto el patriarcado y el sexismo como visiones contrarias a Dios.

Entre las madres de la teología feminista, una laica católica constituye un caso único por su particular repercusión a nivel global: Elisabeth Schüssler Fiorenza. Ella entiende su aporte como «teología crítica de la liberación " ${ }^{50}$ : "la teología feminista presupone, y también tiene como objetivo, una praxis emancipatoria, eclesial y teológica ${ }^{51}$. Una de las características del planteo de Schüssler Fiorenza es que su hermenéutica feminista crítica de la liberación reconoce un "centro hermenéutico», que si bien se asemeja al de otras posiciones feministas que buscan recuperar las experiencias de las mujeres ${ }^{52}$, en ella adquiere una peculiar originalidad: «el centro hermenéutico de la interpretación bíblica feminista es la iglesia-mujeres (ekklesia gynaikon), el movimiento de mujeres identificadas consigo y de varones identificados con las mujeres en la religión bíblica» ${ }^{53}$. Esta Iglesia de las mujeres clama por un proceso feminista de transformación en el centro de la fe y de la comunidad cristiana y exige una reformulación de la eclesiología desde la perspectiva del «discipulado de iguales». En algunas de sus obras como In Memory of Her o Discipleship of Equals, Schüssler Fiorenza aplicará este centro a la crítica

50 Su posición ya es formulada en E. Schüssler Fiorenza, «Feminist Theology as a critical Theology of Liberation", Theological Studies 36 (1975), 605-626. Como valoración de su propuesta liberacionista, ver M. Ескноцт, «Entre la indignación y la esperanza. ¿Investigación Teológica sobre las mujeres como teología de la liberación?», Proyecto 39 (2001), 125-143. Ver también M. A. Hewitt, «Dialéctica de la Esperanza. La teología feminista de liberación de Elisabeth Schüssler Fiorenza como teoría feminista crítica», Anatéllei XI, 22 (2009), 109-123.

51 E. Schüssler Fiorenza, Discipleship of Equals. A Critical Feminist Ekklesia-logy of Liberation (New York 1993), 63-67; la cita está tomada de Antología de Textos de Autoras, 455ss..

52 Cf. V. R. Azcuy, «El lugar teológico de las mujeres», Proyecto 39 (2001) 11-34; "Teologías desde las biografías de las mujeres. Reflexiones sobre el método», en C. Schickendantz (ed.), Mujeres, género y sexualidad. Una mirada interdisciplinar (Córdoba 2003)..

53 E. Schüssler Fiorenza, «The Will to Choose or to Reject: Continuing Our Critical Work», en L. RusselL, Feminist Interpretation of the Bible, 125-136. 
y la reconstrucción de los orígenes cristianos mediante una crítica a las visiones culturales de género y al rol del patriarcado en todas las fases de la vida de la Iglesia y de la sociedad.

En relación con las Escrituras, la autora habla de una «hermenéutica crítica feminista de la liberación», que se entiende como hermenéutica de la sospecha porque "pretende explorar las visiones y los valores liberadores u opresores inscritos en el texto identificando el carácter y la dinámica androcéntrico-patriarcales del texto y de sus interpretaciones" ${ }^{54}$. La otra cara de la interpretación feminista es la hermenéutica de la memoria; ambas van juntas, ya que la hermenéutica de la sospecha está al servicio de una hermenéutica feminista de la memoria ${ }^{55}$. Con respecto a los paradigmas de lectura, la autora plantea que:

«una interpretación feminista crítica para la liberación explora, problematiza y afirma diferentes paradigmas de lectura e interpretación hegemónicas. Su objetivo es desenmascarar los textos y las lecturas de la Biblia que nutren la inscripción de una identidad cultural-religiosa "femenina" elitista, exclusivista, racista, colonialista, deshumanizante o anti-judía cristiana. De esta manera, revee la interpretación bíblica como una praxis argumentativa, persuasiva y emancipatoria que desestabiliza, hace proliferar y energiza las lecturas críticas para la liberación en contextos socio-histórico-religiosos particulares. Al hacerlo busca socavar un modelo fundamentalista de lectura de la Biblia que reclama ser el único correcto y verdadero. (...) la tarea teológica primaria de una hermenéutica liberacionista crítica consiste en escrutar y marcar los textos y las interpretaciones de la Biblia respecto de cuánto promueven el ethos kyriarcal y una visión religiosa deshumanizante que legitima la injusticia y la opresión $\aleph^{56}$.

54 E. Schüssler Fiorenza, Pero Ella dijo, 83-85; el texto citado está tomado de $A n$ tología de Textos de Autoras, 453ss. En este mismo texto, la autora presenta como ejemplo el pasaje de Marta y María en el Evangelio de Lucas: "puesto que los textos bíblicos están escritos en lenguaje androcéntrico en el seno de culturas patriarcales, la hermenéutica de la sospecha no empieza por asumir que el relato de Marta y María sea un texto feminista liberador solo porque sus personajes centrales sean mujeres. En cambio, trata de investigar cómo y por qué el texto estructura el relato de estas dos mujeres tal como lo hace» (453).

55 Cf. E. Schüssler Fiorenza, Bread Not Stone, 19-20, en A. Clifford, Introducing Feminist Theology, 56-57.

56 E. Schüssler Fiorenza, En la senda de Sofía. Hermenéutica feminista crítica para la liberación, Buenos Aires, Lumen, 2003, 104-106; el texto está tomado de Antología de Textos de Autoras, 464ss. El concepto «kyiriarcado» (de kyrios=señor) designa 
Schüssler Fiorenza ofrece una síntesis de su propuesta de interpretación bíblica en Wisdom Ways. Introducing Feminist Biblical Interpreta$t_{i o n} n^{57}$; en esta obra, su punto de partida no es la Escritura, sino los paradigmas de lectura que se adoptan ante ella. Distingue cuatro paradigmas o lugares previos de la interpretación de la Biblia, que no se excluyen entre sí: 1) el paradigma revelatorio doctrinal; 2) el paradigma positivista científico; 3) el paradigma hermenéutico-cultural; y 4) el paradigma retórico-emancipatorio, en el cual inscribe su posición que luego completará en el último capítulo desde su propuesta hermenéutica crítica y sus danzas o pasos ${ }^{58}$ :

\section{«El paradigma retórico-emancipatorio}

En las dos últimas décadas ha ido adquiriendo forma un nuevo paradigma de interpretación que representa un giro científico-hermenéutico, pero también ético-político. [...]

Para ubicarnos teórica y prácticamente dentro de este incipiente paradigma crítico-emancipador, hemos de interrogar a los textos bíblicos y a las preguntas, métodos y estrategias de interpretación acerca de la función que desempeña tanto en la autopercepción política y personal como en las convicciones públicas. Para hacer esto, primero necesitamos analizar cuidadosamente lo que está presente emocional, intelectual o teológicamente, en nuestro compromiso con el cambio de un modelo kyriárquico-eurocéntrico de lectura bíblica a otro radicaligualitario-cosmopolita. [...]

Dado que este cuarto paradigma se encuentra todavía en proceso de articulación y todavía no ha sido capaz de crear sus propias estructuras institucionales, ha resultado difícil otorgarle un nombre adecuado. Alternativamente, lo he desdoblado en el paradigma "teológico-pastoral", "cultural-liberacionista", "retórico-ético", o "retórico-político". Finalmente, me he resuelto por la denominación "retórico-emancipa-

una comprensión del patriarcado no limitado al sistema sexo-género, sino que incluye las estructuras interrelacionadas de dominación masculina sobre individuos o grupos, en las cuales pueden participar tanto varones como mujeres por igual..

57 E. Schüssler Fiorenza, Wisdom Ways. Introducing Feminist Biblical Interpretation (New York 2001). Traducción castellana: Los caminos de la Sabiduría. Una introducción a la interpretación feminista de la Biblia (Santander 2003).

Transcribo, en este punto, la selección realizada por Constanza Levaggi a partir de Los caminos de la Sabiduría. Una introducción a la interpretación feminista de la Biblia, 58-68; a continuación, Schüssler analiza el texto de 1Co 14, 33b-36, desde los cuatro paradigmas. Cf. Antología de Textos de Autoras, 466ss. 
dor" para articular su método y sus objetivos, a saber, interpretar los textos no desde un punto de vista científico-descriptivo, sino desde una perspectiva retórico-política, es decir, en cuanto textos dirigidos a un público con el que entablan una discusión a fin de persuadirlo de algo».

Como valoración general de la propuesta de Schüssler Fiorenza, se puede señalar: 1. Su feminismo teológico y exegético se debe entender en el marco interdisciplinario de la teología de la liberación y de la crítica feminista; 2. la autora formuló preguntas que la mayoría de las/os exégetas feministas ya no pueden ignorar porque establecen estrechas relaciones entre los métodos exegéticos y la hermenéutica bíblica; 3. En su propuesta de lectura se puede constatar que la exégesis feminista no es un método particular de exégesis, sino una perspectiva crítica que atraviesa todos los métodos e interpretaciones vigentes en las ciencias bíblicas $^{59}$. Su postura podría entenderse como forma crítica de la hermenéutica bíblica feminista, según la clasificación que propone el Documento de 1993. A pesar de su influjo generalizado, sus posiciones también encuentran reservas por parte de algunas exégetas que consideran excesiva su utopía feminista con respecto a los orígenes.

Phyllis Bird es otra de las voces pioneras que se hace la pregunta acerca de cómo leer la Biblia, teniendo en cuenta que «el sexismo de la Biblia es penetrante» ${ }^{60}$. Como ejemplo, la autora propone en este texto el caso de las genealogías que nos recuerdan que el mundo bíblico es un mundo de varones; las genealogías son fundamentalmente listas de varones, en las cuales la mujer normalmente no aparece ${ }^{61}$. A Phyllis Bird también le interesa aclarar que es importante mantener el vínculo con la Biblia aunque se trate de un texto patriarcal, porque ella es el fundamento de la

59 Cf. M. Navarro Puerto, «La exégesis feminista del NT con acento extranjero", Sal Terrae (2000), 643-654, y C. Lértora Mendoza, «En Memoria de ella. Una obra clave de Elizabeth Schüssler Fiorenza», en Estudios de Autoras, 395-427.

60 P. BIRD, The Bible as the Church's Book, 91-93; cita tomada de Antología de Textos de Autoras, 108s. Para esta autora, sigo el estudio de A. Pilarski, «Una transversal en el pensamiento de Phyllis Bird. Pasos hacia una hermenéutica bíblica feminista», en Estudios de Autoras, 115-133.

${ }^{61}$ Una excepción es sin lugar a duda la genealogía de Mateo (1, 1-16) que debe quebrar la genealogía para hablar del nacimiento de Jesús, no engendrado por José sino de María: esposa de José, razón por la cual introduce otras cuatro mujeres que preparan la inclusión de María y su situación marital extraordinaria 
comunidad de fe y es fuente de liberación a la vez que se requiere una crítica hacia el patriarcado: «esta fuente de servidumbre es a la vez una fuente de liberación y, desde mi punto de vista, la fuente primaria para una crítica feminista a la opresión patriarcal. Soy feminista porque soy cristiana, y no estoy sola ${ }^{62}$. Esta última afirmación, frecuente entre las teólogas feministas, revela el trasfondo cristiano del feminismo que no es otro que el amor de Dios al ser humano varón y mujer; por más sorprendente o inaceptable que pueda resultar para algunos, el feminismo no se opone al cristianismo. Otro texto interesante es el que trata de la lectura feminista de la Biblia: en él, Bird explica, primero, que entiende «el feminismo como una crítica y una posición constructiva que reclama para las mujeres la plena humanidad»; «el feminismo comienza con una crítica a las formas de pensamiento y organización patriarcales y androcéntricas existentes, y se compromete a la realización de formas alternativas. Es por tanto un movimiento político para el cambio, basado en un análisis social y extraído de la experiencia de las mujeres como fuente primaria para este trabajo crítico y constructivo" ${ }^{63}$. Segundo, la autora plantea que para que una lectura de la Biblia sea feminista se requiere una sola cosa: «un lector/a feminista» ${ }^{64}$; por más obvio y simple que parezca, se trata del punto de partida para una hermenéutica bíblica feminista. Para Bird,

«una lectura describe una forma de producción literaria (¿posiblemente oral?) en que un texto bíblico es interpretado para cierta audiencia, esto quiere decir que no es simplemente una respuesta inmediata y privada al texto sino un acto de comunicación que quiere influenciar a una audiencia más extensa. Para mí, la audiencia anticipada es crítica en la producción de la lectura» ${ }^{65}$.

Al interpretar a Bird, Ahida Pilarski encuentra aquí una de las premisas fundamentales en la construcción de una hermenéutica feminista porque se muestra que la aproximación al texto es dialogal: se separan el horizonte de la producción y el de la recepción. La hermenéutica femi-

62 E. Bird, Feminism and the Bible, 70-72; cita de Antologia de Textos de Autoras, 111.

63 P. BIRD, "What makes Feminist Reading Feminist? A qualified Answer», en H. C. Washington - S. Lochrie Graham - P: Times (eds.), Escaping Eden. New Feminist Perspectives on the Bible (Sheffield 1998), 124-134, 124s. De Antologia de Textos de Autoras, 112-113.

64 P. BIRD, «What makes Feminist Reading Feminist? A qualified Answer», 125.

65 P. BIRD, «What makes Feminist Reading Feminist? A qualified Answer», 125. 
nista incluye todas las acciones de la interpretación bíblica: 1) la formulación del sentido del texto en su contexto social y literario antiguo; 2) el lector/a debe respetar la integridad del hablante antiguo, porque solo así se puede establecer el diálogo que es la base para esta aproximación hermenéutica del texto; 3) la misma interpretación histórica puede ser considerada una actividad feminista en el sentido que lo que hace de la lectura que sea feminista no es el contenido sino la actividad y el producto de la intérprete feminista. En este contexto, según Phyllis Bird, no existe tensión entre el método histórico-crítico y el compromiso feminista puesto que el primero es «un intento del ver el pasado en sus propios términos» y el segundo "un compromiso para cambiar los términos de participación y discurso generados en el pasado ${ }^{66}$. En este sentido, «en el centro de la construcción del discurso de una hermenéutica bíblica feminista está la visión de la realidad del texto bíblico. Este será el punto de partida, de mediación y de llegada ${ }^{67}$. Es por este motivo que Bird insiste en cuestionar las lecturas que se identifican como feministas y no consideran los dos lados participantes del diálogo, a saber, el texto y el lector/a; por lo mismo recomienda no olvidar el primer paso de la interpretación bíblica. A su vez, para que la Palabra divina se convierta en palabra de vida, para toda la humanidad en igualdad, será necesario que esta palabra mantenga la conciencia de la hermenéutica feminista.

\section{Un ESTUdio DE CASO: INTERPRETACIÓN FEMINISTA DE JUAN 4,I-42}

Según Sandra Schneiders, «una interpretación transformativa integral del texto bíblico es una interacción entre un lector/a consciente, abierto al reclamo de verdad del texto y el texto en su integridad, esto es, una interacción que toma en cuenta adecuadamente la compleja naturaleza y las múltiples dimensiones del texto y del lector/a. La exégesis histórico-crítica tradicional, porque se ocupa del texto solo como un documento histórico, es necesaria pero no suficiente para una interpretación integral ${ }^{68}$. En lo que sigue, presentaré su propuesta de hermenéutica

66 P. Bird, «What makes Feminist Reading Feminist? A qualified Answer», 128.

67 A. Pilarski, «Una transversal en el pensamiento de Phyllis Bird. Pasos hacia una hermenéutica bíblica feminista», en Estudios de Autoras, 115-133, 130.

68 S. M. Schneiders, The Revelatory Text. Interpreting the New Testament as Sacred Scripture (Collegeville 1999). En el capítulo 6, la autora explica la interpretación si- 
crítica feminista y su estudio de caso de Jn 4,1-42, en el marco de su exposición sobre las mujeres en el cuarto evangelio ${ }^{69}$.

4.1. El acercamiento de la hermenéutica crítica feminista

Sandra Schneiders propone su acercamiento feminista a la Biblia como una concreción o ilustración de su visión de interpretación integral, sin olvidar otros acercamientos ${ }^{70}$. Su visión se desarrolla en cuatro aspectos que sigo a continuación ${ }^{71}$ :

1) Punto de partida de la crítica feminista: la cuestión central, para las biblistas pioneras, consiste en pensar que la Biblia funciona como un legitimador de la opresión de las mujeres, y esto no solo a causa de las interpretaciones, sino también de los mismos textos; "ipuede el texto bíblico funcionar como texto revelatario, como lugar del encuentro salvífico de Dios, para las mujeres que han despertado a su conciencia feminista? ${ }^{72}$. La respuesta depende de la posibilidad del acercamiento feminista.

2) Critica feminista como crítica liberacionista: Schneiders entiende esta perspectiva tras las huellas de Elisabeth Schüssler Fiorenza, pero realiza una aclaración que considero fundamental: mientras la Biblia se ocupa expresamente de los pobres y oprimidos, no atiende a la opresión de las mujeres, es decir, el texto bíblico no es pura y simplemente un texto de liberación para la/s mujer/es y esto es parte del problema ${ }^{73}$.

guiendo los pasos de la hermenéutica de Paul Ricoeur, distinguiendo la interpretación como proceso y como producto, el mundo delante del texto y la apropiación.

69 Su perspectiva recibe la influencia de Raymond Brown, lo que muestra el diálogo existente entre la hermenéutica feminista y otros acercamientos, cf. R. Brown, La comunidad del discípulo amado, 177-192.

70 De hecho, la autora reconoce y estudia los diversos acercamientos metodológicos al texto: histórico, literario, psicológico y sociológico, de crítica ideológica, teológico -religioso y espiritual, cf. S. M. SchneIDers, The Revelatory Text. Interpreting the New Testament as Sacred Scripture, 114-131.

71 Cf. S. M. Schneiders, The Revelatory Text. Interpreting the New Testament as Sacred Scripture, 180-186.

72 S. M. Schneiders, The Revelatory Text. Interpreting the New Testament as Sacred Scripture, 181.

73 Cf. S. M. Schneiders, The Revelatory Text. Interpreting the New Testament as Sacred Scripture, 182. 
3) Sospecha y recuperación: la interpretación bíblica feminista pertenece, para Schneiders, al tipo de acercamiento de crítica ideológica, el cual asume que el texto no es neutro ni el intérprete objetivo; así se explica la importancia de la hermenéutica de la sospecha, que trata de discernir el lugar de marginación, reducción, demonización y trivialización de las mujeres en los textos y en las interpretaciones realizadas tradicionalmente. La tarea de la crítica feminista es, primero, sospechar del texto y de los intérpretes, pero no acaba aquí: se prolonga, en un segundo momento, cuando se reconoce que el texto bíblico y su interpretación es susceptible de una hermenéutica liberadora.

4) Estrategias de la critica feminista: estas son las estrategias que utiliza la crítica feminista para «liberar el texto» de sus condicionamientos patriarcales y opresivos ${ }^{74}$ :

- Revisar la traducción del texto: se trata de reconocer y corregir la invisibilización de las mujeres en el texto mediante traducciones inadecuadas;

- Focalización del potencial liberador del texto: incluye la focalización del «material sobre mujeres» en el NT, como por ejemplo la formulación de Jn 4,27;

- Dar visibilidad a las mujeres: cuando su presencia, voz, nombre o acción queda oculta en los textos bíblicos, como la proclamación de Jesús como «Salvador del mundo» $(J n$ 4,42) que revela la igual participación de la mujer en la salvación;

- Sacar a la luz los secretos del texto: se refiere a aspectos presentes en el texto, pero que no son percibidos o a veces negados por los exégetas, en este caso la fuerte acentuación de la identidad y la misión de las mujeres en este evangelio;

- Rescatar el texto de malinterpretaciones: mediante la crítica a todas las formas de interpretación de sesgo patriarcal o masculinizante; tal sería el caso de una relativización del talante misionero y religioso de la mujer samaritana.

74 Cf. S. M. Schneiders, The Revelatory Text. Interpreting the New Testament as Sacred Scripture, 183-186. 
4.2. Un estudio de caso: Jn 4,1-42 según la interpretación feminista de Schneiders ${ }^{75}$

1) Presupuestos históricos y literarios. Además del acercamiento feminista, una interpretación integral del texto demanda la explicitación de los presupuestos histórico-críticos y de la crítica literaria. En cuanto a lo histórico, no hay indicios en los Sinópticos de que el Jesús terreno tuviera relación con Samaria: en Lc 9,52-53 se nos dice que los samaritanos rechazaban recibir a Jesús, y en Mt 10,5 Jesús pide a los Doce que no entren en ninguna ciudad de Samaria; en Hch 8 se relata lo que parece ser la primera misión cristiana en esta región, con posterioridad a la muerte de Esteban.

La historia de la samaritana probablemente representa una lectura retrospectiva del ministerio público de Jesús a partir de la experiencia pospascual de la misión en Samaria y la influencia de los samaritanos convertidos en la comunidad joánica ${ }^{76}$. Para Schneiders: «la finalidad básica de la historia de la mujer samaritana en este evangelio es legitimar la misión samaritana y establecer la plena igualdad entre cristianos samaritanos y cristianos judíos dentro de la comunidad $»^{77}$. El relato justificaría esta igualdad en el hecho de que Jesús habría evangelizado a ambos grupos.

Desde el punto de vista literario, se presentan dos características principales:

1. Se trata de una "historia tipo", una narrativa que sigue un modelo bíblico reconocible. En este caso, el modelo o paradigma es la historia que relata un encuentro de futuros esposos en el pozo que es central en la historia de salvación. En efecto, este encuentro tiene lugar junto al pozo de Jacob, que en la tradición judía se identifica con el pozo de Abraham (cf. Gén 21, 25-31) y de Isaac y Rebeca (cf. Gén 24,10-61; de Jacob y Raquel: 29,1-20), así como con la roca de la cual Moisés sacó el

75 Sigo aquí a S. M. Schneiders, The Revelatory Text. Interpreting the New Testament as Sacred Scripture, 186-199, y S. SchneIDERS, «Inclusive Discipleship (John 4:142)», en Written that you may believe. Encountering Jesus in the Fourth Gospel (New York 1999), 126ss.

76 Cf. R. Brown, La comunidad del discipulo amado, 183ss.

77 S. Schneiders, «Inclusive Discipleship (John 4:1-42)», 134-135. 
agua en el desierto ${ }^{78}$. Ya en Caná, Jesús es reconocido como verdadero novio (cf. Jn 2,9-10) y por Juan el Bautista es presentado como el verdadero novio (3,27-30). Ahora este nuevo Novio que asume el rol de Yahvé, novio del antiguo Israel, viene a proclamar que Samaria es parte integrante del nuevo Israel y sobre todo de la comunidad joánica. Es, además, presentado como el séptimo varón -cinco amantes, uno actual que no es marido y Jesús- que entra en contacto con la samaritana, tal vez indicando que es el verdadero novio. La imagen esponsal está subrayada en la relación varón-mujer en el relato del encuentro de Jesús con la mujer samaritana.

2. Lo segundo es que el episodio de la samaritana puede verse dentro de la unidad de los capítulos 2-4 del cuarto evangelio: desde las Bodas de Caná $(2,1 s s)$ hasta la curación del hijo de un funcionario real en Caná (4,46-54) y claramente en contrapunto con el pasaje de Nicodemo -judío-samaritana, hora del encuentro, respuesta a la revelación- ${ }^{79}$.

2) Foco teológico de la historia: la misión. Además de ser un episodio que es parte de la presentación de Jesús como verdadero Novio del nuevo Israel, este relato es sin duda una historia de misión. Esto es evidente por el discurso de Jesús a sus discípulos (4,31-38), por el desenlace de la escena y la conversión de los habitantes de esa ciudad (4,39ss). Jesús habla a sus discípulos de su hambre más profundo, hacer la voluntad del

78 Cf. L. Rivas, «El don de Dios ofrecido a la Samaritana (Jn 4,1-42)», en Sociedad Argentina de Teología (ed.), Gratuidad, Justicia y reciprocidad. Dimensiones de una teología del don (Buenos Aires 2005), 57-67, 60.63: «El agua del pozo de los patriarcas y de la roca de Moisés, como don de Dios, es figura de la Ley y la Sabiduría, pero el Evangelio de Juan muestra que las figuras e instituciones del Antiguo Testamento están en el camino hacia una realidad única que es el mismo Jesucristo. El don de Dios no se agota con el conocimiento de la voluntad de Dios expresada en la Ley y la Sabiduría comunicada por los sabios de Israel: estos son pasos que avanzan hacia una revelación plena de la misma Palabra de Dios».

79 Según Léon-Dufour, la lectura de 4,1-42 se debe ubicar en relación con el relato de Nicodemo en 3,1-21. Nicodemo se presenta como una figura clave entre los fariseos y como un dirigente importante entre los judíos. Viene a Jesús de noche, probablemente por miedo a sus colegas; Nicodemo admira a Jesús, pero en realidad no sabe quién es Jesús. La enseñanza de Jesús gira en torno a la idea de nacer de nuevo: la necesidad de este nacimiento se enraíza en el inmerecido amor de Dios al mundo (3,16-17); quien ha nacido de nuevo tiene que demostrarlo amando como Dios y Jesús amaron a la humanidad, incluso hasta dar la vida (13,34-35). Cf. X. LÉon-Dufour, Lectura del Evangelio de Juan, Jn 1-4 (vol.1) (Salamanca 1993), 269ss. 
Padre, se encuentra saciado $(4,34)$ y el redactor aclara que la conversión de los samaritanos es a causa del testimonio de la mujer en medio de ellos $(4,39)$.

3) La identidad y el rol de la mujer samaritana. Para Sandra Schneiders, la historia de la interpretación de este pasaje, revela un «caso de trivialización, marginación e incluso de demonización sexual de la mujer bíblica, que refleja y promueve un tratamiento paralelo de la mujer real en la Iglesia ${ }^{80}$. La ambigüedad y pecaminosidad de la samaritana en la tradición antigua está documentada en distintos estudios ${ }^{81}$.

Algunas claves dadas por la autora para avanzar en la interpretación son las siguientes:

1. Su identidad se debe entender entre Nicodemo, autoridad judía, y el funcionario real o autoridad pagana; esto significa que, junto a Nicodemo, la Samaritana es una "figura representativa» y tiene un carácter simbólico, de representación colectiva, lo cual alerta al lector/a con respecto a un literalismo sexual en la lectura del texto ${ }^{82}$.

2. La conversación entre la mujer y Jesús es, desde el comienzo, una discusión teológica sobre la fe samaritana y la fe judía, con el telón de fondo de las tradiciones mosaicas y proféticas; el culto yavista samaritano y el judío se presentan bajo la metáfora del matrimonio fiel o adúltero según corresponda.

3. La conversación sobre los maridos, por su contexto, parece más simbólica que literal; además empalma directamente con la incorporación de

80 S. M. Schneiders, The Revelatory Text. Interpreting the New Testament as Sacred Scripture, 188

81 Ver, por ejemplo, H. DE Wit, Por un gesto de amor. Lectura de la Biblia desde una práctica intercultural (Buenos Aires 2010), 23-26. Según J. Norfleete DaY, The Woman at the Well. Interpretation of John 4: 1-42 in Retrospect and Prospect (Biblical Interpretation Series 61) (Boston-Colonia 2002), «se le ha golpeado muy fuerte a la mujer samaritana en la historia de la interpretación de Juan 4. Mientras que hubo una obsesión por la historia de sus matrimonios, hubo poco interés en su rol como aprendiz, como apóstol, como evangelista. Parece abusivo el peso de tradiciones de lectura dominantes, de la cultura, de lo patriarcal y difícil la evasión». Citado por H. DE Wit, Por un gesto de amor. Lectura de la Biblia desde una práctica intercultural, 26.

82 De hecho, la samaritana es la primera persona en este evangelio que recibe la revelación del Yo Soy, lo cual refuerza su significación comunitaria. 
Samaria al nuevo Israel que implica aceptar la revelación de Jesús como el Mesías esperado (cf. 4,26) ${ }^{83}$.

4. Otra clave de interés para ver el rol misionero de la mujer samaritana es considerar el diálogo de Jesús con los discípulos en $4,27 \mathrm{ss}^{84}$.

4) Resultados de la interpretación feminista. La identidad y el rol de la mujer en el episodio estudiado se reveló, a diferencia de la exégesis tradicional, como una figura simbólica representativa del elemento samaritano en la comunidad joánica. Por tanto, el diálogo sobre los maridos se debe entender como metáfora de idolatría y el episodio del retorno de los discípulos, unido al discurso de Jesús sobre la misión, confirman la efectividad de la evangelización realizada por la mujer.

5) Apropiación hermenéutica. Según Schneiders, en ella llega a su momento culminante la interpretación integral, que se manifiesta a través de su efecto transformativo. La interpretación de Jn 4 conduce a un mundo esencialmente caracterizado por lo inclusivo: "nadie es excluido, nadie debe ser excluido, del reino universal del Salvador del mundo» ${ }^{85}$. El/la lector/a feminista también hará la experiencia del "todavía no" de la cualidad de este mundo y por eso queda abierta la tarea de la transformación. La interpretación integral de un texto bíblico, para la autora, es el proceso de compromiso con él de modo tal que pueda funcionar como lugar y mediador del encuentro transformador con el Dios vivo; no en último término, se han de ver aquí las implicancias de un acercamiento espiritual al texto bíblico: su sabiduría es para vivirse.

83 También para León-Dufour, «los cinco "maridos” corresponderían a los cinco dioses introducidos en Samaría después de la conquista asiria del año 721 (cf. 2Re 17,23-41); en este caso, el que tiene ahora la mujer no es el verdadero Dios». X. LÉOn-Dufour, Lectura del Evangelio de Juan, 289.

84 La dimensión misionera también es destacada en otros estudios feministas: L. RiBA De Allione, «Mujeres discípulas en el evangelio de Juan», en Proyecto 39 (2001) 99-123, 106ss; E. Aldave Medrano, «El desafío de una misionera: la mujer samaritana (Jn 4,1-42)», en C. Bernabé (ed.), Con ellas tras Jesús. Mujeres modelos de identidad cristiana (Estela 2010), 199-255; T. Karlsen SeIm, "Las mujeres y las negociaciones sobre el género en el Evangelio de Juan», en M. Navarro - M. Perroni (eds.), Los Evangelios, 223-251, 243s.

85 S. M. Schneiders, The Revelatory Text. Interpreting the New Testament as Sacred Scripture, 196. 
5. EXÉGESIS Y TEOLOGÍA ANTE EL FEMINISMO: UNA ENCRUCIJADA QUE DA QUE PENSAR...

A modo de conclusión, presento algunas reflexiones que pueden servir como síntesis:

- La lectura de la Biblia y la práctica de la teología en la Iglesia requieren atención a toda la comunidad creyente y a las mujeres en particular, porque ellas constituyen un sujeto teológico emergente e impulsan un nuevo acercamiento hermenéutico a la Biblia.

- Como la Biblia es el libro de la Iglesia y la fuente del cristianismo, la relación entre Biblia, teología y mujeres resulta una clave esencial de investigación y reflexión, tal como lo han percibido las autoras feministas pioneras del siglo XX.

- El desarrollo epistemológico de los estudios de mujeres, estudios feministas y estudios de género ha crecido notablemente en las últimas décadas y su recepción crítica en la exégesis y en la teología supone una tarea colectiva de estudio, discernimiento y conversación interdisciplinaria que recién está comenzando en nuestro ámbito.

- El Concilio Vaticano II nos propuso una teología de los signos de los tiempos y su actualización no puede excluir la cuestión de la/s mujer/es: en cada país, en cada tradición religiosa, en cada comunidad de fe, en cada institución católica, en cada disciplina ¡cómo evaluamos nuestra situación?, ¿qué podemos hacer nosotros/as?

- El nuevo sujeto feminista, mujeres y varones, impulsa una transformación de los discursos y las prácticas en orden a un modelo más igualitario, a la vez que realiza un análisis crítico de las representaciones y los discursos deudores del androcentrismo que sostienen una dominación masculina a costa de una subordinación femenina.

- La encrucijada de un feminismo cristiano invita a un proceso de aprendizaje y de conversión: crear espacios de diálogo y escucha, darse cuenta de la realidad de la discriminación por sexo y género, y comprometerse con los cambios necesarios.

- ¿Qué es, entonces, lo bueno del feminismo, de la teología feminista, de la hermenéutica biblica feminista? Se trata de entrar en contacto con las propuestas de acercamiento feminista y las teologías feministas en 
su diversidad generacional, étnico-cultural, denominacional, para averiguarlo, probarlo y discernirlo.

- Letty Russell piensa que es el camino para «liberar la Palabra que libera»: liberar el potencial salvífico de la Palabra a la vez que criticar el sesgo patriarcal de los textos y sus intérpretes; la Palabra nos libera del sexismo para una nueva humanidad.

- Elisabeth Schüssler Fiorenza entiende la hermenéutica crítica feminista como un "paradigma emancipatorio" que permite la reconstrucción del cristianismo.

- Phyllis Bird propone un proceso hermenéutico dialogal cuya base siempre sea el texto bíblico: que articule los métodos histórico-críticos con la hermenéutica feminista, para la cual se requiere un/a lector/a feminista. Su aporte se encuadra en las perspectivas generales recomendadas por el Documento de la Pontificia Comisión Bíblica.

- Sandra Schneiders coincide en la necesidad de los métodos históricocríticos, pero a la vez sostiene su insuficiencia: una interpretación transformativa integral busca llegar hasta el momento de la apropiación de la sabiduría del texto para la vida.

- El acercamiento feminista a Jn 4,1-42 evidencia que una interpretación tradicional puede ser enriquecida, descubre la figura misionera de la mujer samaritana y la inclusividad como camino de transformación hacia un «discipulado de iguales».

El feminismo como cuerpo de estudios teóricos presente en el ámbito académico universitario representa una encrucijada para la exégesis y la teología contemporánea. El desarrollo de la hermenéutica bíblica feminista y de las teologías feministas en el ámbito cristiano de fines del siglo XX y principios del siglo XXI da que pensar, exige una recepción y plantea la oportunidad de un diálogo provechoso para mujeres y varones. Las orientaciones de la Pontificia Comisión Bíblica de 1993 nos invitan a profundizar lo bueno que se ofrece en las diversas formas del acercamiento feminista en la lectura de la Biblia. 
Resumen: El desarrollo creciente de la interpretación feminista de la Biblia y de las teologías feministas, cuyas perspectivas buscan impulsar la dignidad de las mujeres y de toda criatura desde la fe cristiana, plantea importantes desafíos para la exégesis y la teología como disciplinas. En este estudio se intentan una presentación general de la teología feminista y un diálogo con cuatro pioneras norteamericanas del área bíblica, que en parte se basan en aportes de la investigación colectiva del Programa Teologanda que se realiza desde 2003 en la Argentina. A modo de ejemplificación, se expone una interpretación feminista de Jn 4,1-42 según Sandra Schneiders y se concluye con algunas reflexiones abiertas sobre la temática propuesta.

Palabras clave: interpretación de la Biblia en la Iglesia, acercamiento feminista, perspectiva de las mujeres, teología feminista, interpretación feminista de la Biblia.

Abstract: The increasing development of the feminist interpretation of the Bible and of feminist theologies, whose perspectives seek to promote the dignity of women and of all creatures from the standpoint of the Christian faith, poses major challenges for exegesis and theology as disciplines. This study attempts to present an overview of feminist theology and a dialogue with four American pioneers of the biblical area, which are partly based on contributions from the collective research of the Teologanda Program that has been conducted since 2003 in Argentina. As an example, a feminist interpretation of Jn 4,1-42 according to Sandra Schneiders is presented as well as a conclusion with some open reflections on the proposed subject.

Keywords: interpretation of the Bible in the Church, feminist approach, female perspective feminist theology, feminist interpretation of the Bible. 